\title{
Retraction Note to: Toeplitz Matrices Whose Elements are the Coefficients of Starlike and Close-to-Convex Functions
}

\author{
D. K. Thomas ${ }^{1}$ - S. Abdul Halim² ${ }^{(D)}$
}

Published online: 13 March 2018

(C) Malaysian Mathematical Sciences Society and Penerbit Universiti Sains Malaysia 2018

\section{Retraction Note to: Bull. Malays. Math. Sci. Soc. (2017) 40:1781-1790 https://doi.org/10.1007/s40840-016-0385-4}

The authors have retracted this article because the article contains major flaws in the proof of the main results. The results of the paper are invalid, since the assumption that the functionals considered are rotationally invariant is not valid. All authors have agreed to this retraction.

The original article can be found online at https://doi.org/10.1007/s40840-016-0385-4.

S. Abdul Halim

suzeini@um.edu.my

1 Department of Mathematics, Swansea University, Singleton Park, Swansea SA2 8PP, UK

2 Institute of Mathematical Sciences, University of Malaya, 50603 Kuala Lumpur, Malaysia 